\title{
Bosnian/Croatian/Serbian Heritage Speakers in Four Major U.S. Metropolitan Areas: Resources for the Attainment of Full Professional Linguistic Proficiency ${ }^{1}$
}

\author{
Danko Šipka \\ Arizona State University
}

\begin{abstract}
The present study analyzes heritage learners of Bosnian/Croatian/Serbian (BCS) from four major U.S. metropolitan areas. The focus is on the prospects of their attaining full professional language proficiency. Several major factors in language maintenance and the possibility of attaining full professional proficiency in the language are identified. The design and testing of a syllabus for heritage language speakers is provided and discussed. The author concludes with a call for the creation of a BCS heritage language centre as a durable solution for providing heritage language learners a path toward full professional proficiency.
\end{abstract}

Keywords: heritage speakers, Bosnian/Croatian/Serbian, full professional proficiency, language maintenance.

\subsection{INTRODUCTION}

$\mathrm{T}$ he present research work, applied in its core, studies the prospects of the attainment of full professional language proficiency by Bosnian/Croatian/Serbian (henceforth BCS) heritage speakers in four major U.S. metropolitan areas. The project is centred on the following two principal goals: (a) to survey BCS heritage speakers' potential and needs, and (b) to propose a new course tailored to these heritage learners' needs. Another aim is to investigate the linguistic and cultural foundation of heritage speakers, with a future goal of building a cadre of speakers with ILR (Interagency Language Roundtable) 3-full professional linguistic proficiencycommand of BCS (see details below). This particular proficiency level enables the speaker to function professionally in BCS, and is crucial in numerous government services, such as military and intelligence,

1 I would like to extend my gratitude to the two anonymous reviewers, whose comments contributed to the improvement of the original draft of this paper. This research was funded by an American Council of Learned Societies grant in 2010-12. 
diplomacy, and international economic cooperation, among others. At the same time, various industrial entities and non-governmental organizations need a cadre of speakers at this level for their projects in BCS-speaking countries. The attainment of ILR 3 empowers the students with real-life skills, which is certainly one social responsibility of any language-learning centre or program. With numerous heritage speakers being at ILR 2 and 2+, it is natural to see them as a group with a high potential of eventually reaching ILR 3.

The present study first introduces the topic and provides a brief overview of literature in the field, as well as methodology and instrument utilized. The qualitative analysis reports on extensive fieldworkspecifically, data obtained from interviews with a number of participants. The quantitative analysis focuses on results obtained from an online survey. The results of both analyses are incorporated into a discussion of the new proposed and tested syllabus. The study concludes with recommendations for the future development of BCS heritage language (henceforth HL) instruction.

\subsection{BACKGROUND}

Brinton and others have recently augmented an already heightened interest in heritage speakers during the last decades with their synthesizing volume, which provides an excellent review of the main studies in the field. The foundation of the Heritage Language Journal, establishment of the National Heritage Language Center, and creation of the Alliance for the Advancement of Heritage Languages are some of the developments in this field (see Heritage Languages in America). In what follows, I provide a review of literature directly relevant to the research objectives of the present article. (Studies that focus on heritage speakers as a test ground for syntactic and other theories are not discussed.)

Key factors that influence language maintenance and language enhancement among heritage speakers constitute one area of research inquiry in the field. Chhuon discusses various less commonly taught languages (LCTLs) and identifies the crucial role of ethnic identity and family relations in heritage language learning. Tatar, in her qualitative investigation of Turkish heritage speakers, studies the following factors: the role of the parents, visits to the heritage country, and the role of school and heritage community in the development and maintenance of the heritage language. Moreira Flores concentrates on the language input to which heritage speakers of European Portuguese in Germany are exposed. She identifies the limitations of that input in family interactions and heritage language programs alike. Kondo-Brown addresses various motivational mechanisms 
of language acquisition in heritage speakers. Rothman investigates Brazilian Portuguese speakers and notes:

Since the heritage language is the family language used and heard in restricted environments, there are varying degrees of deterministic consequences for the complete acquisition and/or maintenance of the heritage language, depending on when and how the societal majority language is introduced (i.e., simultaneously or successively). (360)

Lee, in studying Korean heritage speakers, observes that

the dichotomous distinction between heritage and non-heritage language learners may be limiting in capturing the full range of characteristics of language learners. [Our] data illustrate that there are many learners who seem to possess characteristics of both heritage and non-heritage language for various reasons, which would not be captured if we were to only look at learner profiles in an either/or scenario. (562).

Lee approaches heritage speakers somewhat differently from the general trend, viewing them as a category opposed to and isolated from non-heritage speakers.

Attempts to take concrete action in the field of heritage language learning, aimed at improving the rate of maintenance and effectiveness of instruction, are another major direction in field. Peyton and others set a broad action agenda for heritage language preservation. Carreira and Kagan analyze survey results for various heritage languages (Spanish and 12 LCTLs) and succinctly formulate the following recommendations: "Know the Learner," "Know the Community," and "Connect the Learner and the Community" (59-60). Cummins calls for the abandonment of monolingual teaching practices and concludes: "Affirmation of students' home languages within the school and in after-school programs can play a crucial role in encouraging heritage language speakers to view their multilingual talents as a valued component of their identities" (590). Polinsky and Kagan analyze the attractiveness of heritage speakers in linguistics and language pedagogy and point out that

[t]he introduction of heritage language courses reflects the acknowledgment that heritage language speakers are a very special group, and in some sense a severely underutilized national resource; with proper instruction, they are much more likely than any second language learner to achieve near-native linguistic and sociocultural fluency. (390).

In the Slavic field, research work by Kagan and others brought tangible results to teaching and learning Russian by heritage speakers. Other Slavic languages, notably BCS, have not commanded noticeable interest. There are no qualitative or quantitative accounts of the heritage population of BCS in 
the United States, aside from occasional reviews of teaching programs, such as Šipka and Dunatov. ${ }^{2}$

In 2009, the U.S. Census Bureau showed the following distribution of BCS (labelled "Serbo-Croatian") heritage speakers, according to the 2000 census data. There are 233,865 heritage speakers of BCS in the entire United States, with the highest numbers in the following nine states: New York $(31,553)$, Illinois $(29,631)$, California $(23,872)$, Ohio $(12,577)$, Michigan $(11,950)$, Florida $(11,654)$, New Jersey $(10,420)$, Pennsylvania $(8,648)$, and Arizona $(7,438)$ ("Detailed List of Languages"). If one takes into the account factors such as the recent migrations of these speakers to the Southwest, the gravitation of potential students toward university centres (e.g., from New Jersey to New York City), the size and availability of BCS university programs (see Šipka and "Annual Census of College Enrolment"), and the concentration of such speakers (e.g., the fact that a decisive majority of Arizonan heritage speakers is in the Phoenix metropolitan area while the remaining heritage speaker population is widely dispersed in most other locations), one can safely estimate that the highest concentration of BCS heritage speakers with language learning potential can be found in the following four metropolitan centres: New York, Chicago, Los Angeles, and Phoenix. $^{3}$

Since one applicable goal of the present study is to address the prospects of attaining full professional proficiency (ILR 3) in the heritage language, I shall provide some basic information about this particular proficiency scale. The ILR scale (Herzog) is used as a measure of language proficiency in this study because it is one of the commonly used scales in the U.S. and is officially recognized by the U.S. Department of State. In brief, the scale ranges from 0 (no knowledge of the language) to 5 (very well educated native speaker). Number 3 on this scale represents full professional proficiency (i.e., the ability of the learner to perform his/her job in a given language). This scale measures linguistic proficiency in reading, listening, speaking, and writing (please note that recently, translation/interpretation and cultural

\footnotetext{
2 One should note that BCS comprises three or four ethnic standards (or variants): Bosnian, Croatian, and Serbian, as well as Montenegrin (viewed by some as a subset of Serbian and by others as a separate variant). The relations between these ethnic standards are most intricate. For more information about these complex sociolinguistic relations, one should consult sources such as Greenberg and Kordić.

3 The 2011 census, which was made available only after completion of the present research, confirms this trend, presenting an even higher number of Serbo-Croatian speakers: 269,624 (Ryan 3).
} 
proficiency were added to the scale; these are not considered in the present study). ${ }^{4}$

\subsection{GENERAL RESEARCH DESIGN}

The present research study on BCS heritage speakers was devised to include the following seven procedural phases: (a) general orientation, initial design, and literature review; (b) data collection in the four aforementioned metropolitan centres; (c) writing of the preliminary report; (d) design of the online survey; (e) online data collection; (f) design and testing of the syllabus and its proposed modification; and (g) analysis of the results, presented here.

In research design and with respect to methodological considerations, I conducted a series of on-site structured open-question interviews. I transcribed and analyzed the interview data qualitatively. In addition, I distributed closed-question surveys to participants of the study. These results were collected, classified, and analyzed quantitatively, following the research methodology of Creswell. For the design of the syllabus portion of the study, I consulted the principles of several contrastive and cognitive linguistic approaches, as well as the ILR guidelines (Herzog).

In sections 4 and 5, I discuss the specific methodological details and tools deployed in the present study.

\subsection{FIELD-RESEARCH AND INTERVIEW DATA RESULTS}

I conducted the study from May 2010 to December 2012. During the initial stage of the project, I created a website with detailed background and information about the project (www.asusilc.net/heritage or www.public.asu.edu/ dsipka/heritage). The link was sent to all intended interviewees, including language teachers, heritage community organizers, heritage language students, and their parents. I collected the first set of data in Los Angeles, with substantial assistance from Professor Olga Kagan, an expert on Russian heritage speakers. I used the heritage learners' questionnaire developed by Kagan to collect data for the present study. This questionnaire was distributed via SurveyMonkey (online software for surveys and questionnaires). I collected the next sets of data in New York,

\footnotetext{
${ }^{4}$ For correspondence of the ILR scale with other major language proficiency scales, such as ACTFL (American Council on the Teaching of Foreign Languages), CEFR (Common European Framework), and the Canadian Language Benchmarks, see Lussier (61-70).
} 
Chicago, and Phoenix; details are provided below. The survey developed by Kagan was adapted and modified to tailor BCS data collection objectives. I posted the adapted survey at: www.surveymonkey.com/s/bcsheritagespeakers. ${ }^{5}$

I completed the field research as planned, consisting of: (a) data collection in/around Los Angeles in August 2010, with a visit to Los Angeles from August 13 to 17; (b) data collection in/around New York in September 2010, with a visit to New York from September 17 to 20; (c) data collection in/around Chicago in October 2010, with a visit to Chicago from October 22 to 25; and (d) data collection in/around Phoenix (the author's area of residence) in November 2010.

In addition to thirty heritage students, I interviewed also parents, BCS instructors, university administrators, diplomats, community organizers, religious leaders, journalists, and business owners (for a total of over sixty people). I used the following script for a structured interview with heritage students:

1. Warm-up, pleasantries

2. Personal background (general education, education in the HL)

3. Family background (arrival to the U.S., general education, education in the HL)

4. Community background (friends, clubs, visits to the HL country)

5. Habits (how often and with whom do they speak the HL)

6. Motivation (their own, parents')

7. Aspirations (work, community, etc.)

8. Self-assessment (general, the four skills)

9. Wind-down.

In addition, I visited numerous heritage places (restaurants, stores, bookstores, clubs, places of worship, and the like) in order to contextualize the interview data received. ${ }^{6}$

In what follows, I present the results obtained from the interview data, with emergent themes.

a. The role of the parents in maintaining BCS as the heritage language is paramount and irreplaceable. This was an almost automatic answer in all categories of the abovementioned respondents when addressing the question of why some people retain their heritage language and others do not. Moreover, an organizer of a failed BCS preschool project in New York claimed that the children spoke mostly English owing to the indolence of

\footnotetext{
5 The author is grateful to Olga Kagan for her extensive assistance with the survey stage of the project, and for the opportunity to adapt her heritage survey to the objectives of the present study.

${ }^{6}$ This information is chronicled in the following photo album, with captions detailing the locations: picasaweb.google.com/111643791604289055300/nasijenci.
} 
their parents in interacting in the heritage language. This is consistent with other studies in the field (see Chhuon, Tatar, Kondo-Brown, and Rothman, discussed in Section 2). In the survey, I included a question about one's parents' attitude toward their heritage language in order to learn whether this generally observed phenomenon could be identified in this particular population (as we know from numerous studies of heritage speakers: "one size does not fit all"). It seems that the loss of language among heritage speakers, in addition to sheer inaction on the part of the parents, is also driven by the parents' desire to facilitate their children's socioeconomic advancement. If this preliminary finding is confirmed in the survey, any heritage learner project would need to include a strong outreach component toward parents, both directly and through community organizers, religious leaders, and the like. One extremely important point is to explain to the parents that losing one's heritage language is not a prerequisite for socioeconomic advancement-that, in sharp contrast to this erroneous assumption, bilingualism can be a key to success.

b. A high concentration of BCS heritage speakers and the existence of heritage places in a given neighbourhood are important. This theme became apparent not only in the interviews but also in the accounts about BCS children in Astoria who failed English-language entrance exams into the New York school system (given that they used BCS on a daily basis rather than English). In the survey, I included questions about the concentration of heritage speakers and the frequency at which the respondents visit heritage places. While the role of the parents is unquestionable, the role of the neighbourhoods is limited and transitory. The example of Jackowo, which has been losing Polish speakers to other, more affluent neighbourhoods, shows that as heritage speakers climb up the socioeconomic ladder, they tend to disperse by relocating to various other areas, and as a result, some traditional places change their demographic structure completely.

c. There is a pattern in which one's heritage is lost. Initially, linguistic culture is lost to strong English interference. This is followed by general language and culture competence loss. Folk elements and other similar formal manifestations of the background are lost next, with food constituting one of the final heritage elements to phase out. Illustrative in this regard are several heritage communities under investigation. First, the Serbian community around St. Nicholas Church in Phoenix comprises newer immigrants (mostly from the 1990s wars), where Serbian is spoken but with strong English interference. In contrast, members of St. Sava Church in the same city are mostly post-World War II migrants, most of whom do not speak Serbian but engage in cultural, folk, and other heritage activities. Finally, there are some older heritage neighbourhoods such as the Croatian community of San Pedro, where a famous restaurant serves Croatian food but nobody in it speaks Croatian, and where other identity markers are not 
prominent. Recognizing this pattern is important in that through it, one can identify entry points through which communication with prospective heritage learners can be achieved with common references-for example, to slivovitz or ćevapčići.

d. There is a strong preference among the interviewed students for yearlong online courses rather than for summer on-site courses. I included a question about this preference in the online survey (results are discussed below).

e. Among the respondents, there is a prevalent awareness of one's own lack of accuracy (grammatical, stylistic, correctness, etc.) and a strong desire to rectify this perceived problem. Kagan's survey, adapted in this study, includes a section addressing linguistic self-assessment and other questions related to heritage learners' aspirations. I retained these questions in the survey.

f. Similarly, awareness by heritage speakers of their deficiencies in writing and other formal forms of expression was ubiquitous in face-to-face interviews. Questions addressing this type of awareness are a part of Kagan's survey and are retained in the adapted survey.

g. In contrast to heritage speakers' awareness of their inadequate writing skills and inability to function properly in formal situations, there is an inflated sense of the ability to communicate orally and of one's receptive skills in general. The interviewees would typically note that they speak fine but experience problems in writing; they can understand everything but have problems when it comes to expressing themselves. Kagan's survey includes several questions that address the points raised above; thus they are retained in the adapted survey. If these noted results prove to be valid, the envisaged course will need to include mechanisms for raising students' awareness about their deficiencies in speaking and comprehension.

h. The state of university programs in high-concentration BCS heritage speaker areas is quite limited, with Arizona State University being the only exception. The most surprising discovery was that a long-standing BCS program at the University of Illinois at Chicago, in which the great majority of students were heritage speakers, was recently terminated. The current department head responded laconically to my question about the program with the answer that they offer only Russian and Polish because the BCS specialists retired. My interview with a professor emerita of that program confirmed that one could not expect any improvement in this problematic situation. The situation was not very optimistic in other established BCS programs, either. In a November 2011 e-mail communication, Professor Gorup, retiring from Columbia University, stated that no replacement was envisaged for her imminent retirement. In most other Slavic programs in the country, BCS is not offered at all, and even in those places where it is offered, exchange visitors or graduate students teach it, rather than permanent staff. 
This finding further emphasizes the need for a heritage speaker course that would be available to all interested students from a variety of institutions, even those who could not afford taking two months off work for this course.

i. It is a well-known fact that a proposed class for heritage learners of BCS would be burdened with interethnic tensions. Such a postulation was partially confirmed by the interview data. Large disparities in the level and severity of these tensions seem to exist throughout the locations studied. Indeed, as the interview data show, respondents from the New York City area expressed multi-ethnic and tolerant attitudes, while respondents from LA and Chicago displayed more intolerance and more tensions in their interethnic perceptions. For example, the study of contexts in which heritage speakers live and operate shows interesting results. Specifically, most heritage restaurants visited in New York City as a part of this study, have a multi-ethnic staff, and some of them, such as Marshall (named after Joseph Broz Tito), are multi-ethnic in their name and nature. On the other hand, some participants noted that it was dangerous to declare oneself as a Serb in the San Pedro Croatian community, and others noted that some Albanians were mocked at a Chicago Serbian newspaper anniversary party. Moreover, as evident from the interview data, in all three communities there is also intraethnic conflict: between Yugoslav-oriented Croatians from Komiža and nationalist-minded Croatians in San Pedro; among Serbian church communities with different political orientations in Chicago; and between more moderate and more radical Bosnian Islamic communities, to name a few. In the survey, I included a question about the ethnic format (segregated or mixed) of the prospective class, as any BCS heritage project is faced with negotiating these intricate relations.

j. One evident problem in maintaining BCS is the wide dispersal of its population. In the example of Los Angeles, according to one Croatian community organizer, a lack of interest in language classes for school-age children is evident, and the key problem is the vast dispersion of potential students. This is in sharp contrast to compact heritage communities such as Astoria in New York, where language is maintained with much more success. As previously noted, this dispersion trend further emphasizes the need for developing online courses. In the survey, I included a question about such needs and desires on the part of heritage learners, including those living in areas with a high concentration of BCS heritage speakers.

k. From the interview data, a general impression emerged that diplomatic representatives of Bosnia, Croatia, and Serbia, who have the potential to contribute to the preservation of BCS as a heritage language in the United States, exhibit little or no real interest in this issue. Their actions are almost exclusively declarative rather than substantive. The data show that questions diplomats receive about heritage speakers (even though the reference is to Bosnian, Croatian, or Serbian individually, not BCS) are often 
received as an annoyance. Therefore, with respect to new course considerations, one may not rely on much support from diplomatic representatives.

As presented above, the interview data yielded some important results, which are in need of further elaboration and clarification. Below I present my analysis of the online survey data.

\subsection{ONLINE SURVEY RESULTS}

The online survey was designed by modifying Kagan's survey, adapting to include the parameters and themes that emerged during the analysis of the interview data. I approached all heritage centres visited during the fieldwork, university centres teaching BCS, and various other personal contacts, with a request to encourage heritage language learners to fill out the survey. ${ }^{7}$

I analyzed the survey results using descriptive and inferential statistics. The former focused on the parameters of the sample and on selected issue dimensions, such as a desire for separate ethnic classes or not, on-site or online instruction, and the like. The latter approach used Pearson's correlation coefficient to investigate the association of another set of relevant parameters. I discuss these segments of analysis in turn.

\subsection{DESCRIPTIVE STATISTICS}

\subsubsection{The Parameters of the Sample}

In the present sample, which encompassed 154 respondents, there is a plurality of those who called their language "Serbian" (37.9\%; item 1 of the Survey ${ }^{8}$ ), which generally mirrors the structure of the immigrant population in these four areas (the Bosniak heritage community comprises mostly new immigration, and the Croatian mostly old immigration, while Serbians were equally present in all immigration waves). It is interesting to note that the percentage of those who are indifferent toward ethnic divides is very high.

\footnotetext{
7 Given that the survey (i.e., not an experiment) was completely voluntary, with consent on the part of respondents, and fully anonymous (not requesting participants to reveal their identity in any way), the request for approval from the Institutional Review Board was deemed unnecessary by the author and remains the full responsibility of the present author.

8 The summary of results of the survey is provided at: www.asusilc.net/heritage/surveysummary.pdf.
} 
Nearly one-third of the sample refers to the language neutrally, either "our language" or "Serbo-Croatian" (other choices were Bosnian, Croatian, Montenegrin, Serbian, and Other).

Undergraduate university students comprise the majority of respondents in the sample, approximately half, with students at all levels comprising two-thirds of the sample. The same proportion of undergraduate university students is found in the structure of those interested in the study of languages (item 2 of the Survey).

Nearly two-thirds of all respondents are women (item 4), which may be related to a general gender imbalance in the interest in language study.

The sample is evenly distributed in terms of age and university majors (items 5 and 8, respectively). One-third of the respondents still live with their parents as opposed to two-thirds who live elsewhere (item 9), which limits the influence that parents can have in language maintenance.

Two-thirds of the respondents were born in the BCS target countries (most of them in Bosnia: 37.3 percent). The respondents left their home country at various ages, and many of them came to the United States via some other country, most typically Germany. Therefore, another language, in addition to English and BCS, could be a factor in their linguistic development. Over one-half of the respondents from the sample had some schooling in their heritage country (items 10,11,12, and 13).

One distinct disadvantage of this particular sample is the fact that fourfifths come from the Phoenix metropolitan area (item 40). This makes the sample Phoenix-centric. Although I distributed the call to fill out the survey to all institutions and individuals visited during the fieldwork, the enthusiastic response came mostly from the Phoenix metropolitan area, probably owing to my own close personal contacts as a long-standing instructor of BCS at Arizona State University. While this fact introduces some limitations to the analysis, one should say that most of the students from Phoenix moved to the area only recently, most commonly from Chicago, which makes the sample more representative (in that some of those in Phoenix also reflect the preferences of those in Chicago and other areas from which they came to Phoenix). Similarly, the issues analyzed in this research are not likely to be influenced by one's place of residence in the United States.

Most respondents have the experience of travelling to their heritage countries (only 6\% lack such experience, while one-third travel there annually; item 15). In contrast, $80 \%$ of the respondents live outside of the heritage speaker-dominated areas (item 39). However, nearly $80 \%$ visit heritage venues at least once a year (item 41).

Having the aforementioned limitations in mind, I will now proceed with discussing the language use history by respondents of this sample.

Over fifty percent of respondents (58.4\%) report speaking BCS at home, while English dominates in conversation with friends, as reported by $52 \%$ of 
the respondents. It is interesting to note that both at home and with friends, there is a solid percentage of those who use a mix of the two languages (35.6\% at home and 39.9\% with friends; items 17 and 18, respectively). The sample thus exhibits a typical heritage speaker pattern, with the heritage language dominant at home, English dominant elsewhere, and ample codeswitching domains. This is highlighted by the fact that $54.3 \%$ prefer to speak a combination of BCS and English (item 16).

Developmentally, there is a clear pattern of switching from the dominant usage of BCS before the age of twelve to a mix of English and BCS in later years (item 19).

Two-thirds of the respondents from the sample acquired BCS first, while the remaining third is evenly divided into those who learned English first and those who learned both languages at the same time (item 38). One characteristic of this sample is that a solid majority of $77.7 \%$ never studied BCS in a heritage school (item 21).

Approximately one-third of the respondents from the sample studied BCS in a university setting, one-half of which took heritage speaker courses and the other half took some other BCS classes (item 46). Notably, the most frequent out-of-class activity in respondents' heritage language is speaking over the phone, with activities on the Internet at second place (web pages and e-mail) and listening to music being third (item 37).

In terms of the respondents' attitudes and self-assessment, prominent is a very strong positive general attitude toward learning of BCS. The majority (97.9\%) responded that their families want them to learn BCS, and a similarly high percentage (97.3\%) want to teach their children to speak BCS (items 25 and 27, respectively). Likewise, a prevailing majority of respondents (94.1\%) find their heritage language to be an important part of who they are, while $85.7 \%$ consider it a valuable skill and $77.3 \%$ regard it as something useful (item 53).

The general assessment of the four skills (speaking, listening, reading, and writing) shows an interesting pattern. While English language skills (item 24) remain almost perfectly balanced (with approximately threefourths self-assessing native or native-like proficiency in all four skills), the self-assessment of the BCS skills (item 23) displays a clear imbalance, with listening being assessed as native or near-native by $73.2 \%$ of the respondents, speaking by $57.7 \%$, reading by $47 \%$, and writing by only $38.9 \%$. Looking beyond this general assessment into the self-assessment of concrete tasks within each skill, in reading (item 36), the easiest materials are children's stories and the most difficult are religious texts. In speaking (item 49), the respondents rate formal forms of expression to be more difficult: for example, only $24.6 \%$ of the respondents find giving a formal presentation easy, and $73.1 \%$ believe it is easy to be rude in their heritage language. In listening (item 51), tasks are not so diversified in their difficulty, 
but here again, understanding a formal talk is the most difficult (58.6\% of respondents find this task easy) and listening in on a conversation is the easiest (76.9\% of respondents find this task easy).

I now turn to relevant issues addressed by the survey.

\subsubsection{Relevant Issues}

I address relevant issue dimensions affecting the class design by stating the dimension and then providing descriptive statistics related to the dimension in question.

a. Separate ethnic classes vs. mixed class

A sound majority is comfortable with (or at least amenable to) three (or four) ethnic standard languages being taught in a single class. There is, however, a substantial minority of $25.7 \%$ who have a vested interest in separate classes (item 45). In this situation, a modular type of class structure would be able to reconcile these contrary tendencies.

b. Online vs. in-class instruction

The plurality of those who prefer online to traditional classes does not seem to be very strong (40.5\% vs. $34.2 \%$ ). However, if one includes the fact that only slightly more than one-third of those interested in on-site courses would actually be able to travel to the course location, it is quite clear that the online version of the course offers considerably higher potential (items 43 and 44). One should also note that only $65 \%$ of the respondents were interested in heritage language classes (item 42).

c. Types of learning and teaching materials and activities

Although there are needs for various types of materials, short stories are conspicuously the most desired class material, with $82.4 \%$ support of those who responded, followed by newspaper and magazine articles, with $58.3 \%$ each. This kind of evidence points to the need to incorporate these two kinds of materials (short stories and journalistic texts) into the curriculum to generate more interest in enrollment (item 47).

d. Preferred class outcomes

As evidenced in item 52, expanding vocabulary turned out to be the most desirable class outcome: $61.1 \%$ of the respondents marked this outcome as very important, followed by the need to improve grammatical accuracy (54.9\%). Among the four skills there was a slight preference for improving writing and speaking (47.8\% and $46 \%$, respectively) over reading and listening (42.9\% and 37.2\%, respectively). The class design needs to take all these factors into consideration, most particularly the strong desire to expand vocabulary and improve grammatical accuracy.

Having addressed the most relevant descriptive statistical measures related to the respondents and the issue dimensions relevant for the class 
design, I now turn to examining relations between several key parameters of this research, using inferential statistical analysis. Looking into these relations should show which of the elements in heritage learners' family and social background may be associated with higher self-assessment and willingness to participate in heritage language courses.

\subsection{INFERENTIAL STATISTICS}

This section of the article is devoted to the relation between various developmental parameters of the sample, on the one hand, and selfassessment and language learning interest, on the other. The idea of this segment of research is to determine which elements of heritage language development might be correlated with a higher self-assessment and higher interest in heritage language learning. I coded the data in such a manner as to allow the use of Pearson's correlation coefficient. On the one hand, I chose this particular inferential statistical measure based on the data type. All pairs of variables that were tested were ordinal scales, e.g., the frequency of visits to the heritage country and proficiency self-assessment. Both are discrete scales going from higher (more visits and higher proficiency) to lower (fewer visits and lower proficiency). On the other hand, I chose the Pearson's correlation coefficient because of the nature of the results it produces. I am interested in the strength of correlation between the pairs of variables, and this particular inferential statistical measure produces desirable results, showing positive correlation from above 0 (no correlation) to 1 (full positive correlation) and negative correlation from below 0 (no correlation) to -1 (full negative correlation). Given a normal data distribution, in the present analysis I gave preference to Pearson's over Spearman's correlation. As demonstrated below, I use the strength of particular correlations to explain language maintenance and acquisition aspirations, as well as to design the syllabus for heritage speakers.

a. Parents' attitudes (item 22) vs. self-assessment (item 23) and interest (item 42)

Parents' attitude is coded as follows: "They insisted that I should speak my HL at all times" - 3; "They left the decision about my HL to me but they encouraged its use" - 2; "They did not in any way influence my use of my HL" - 1. I distributed the "Other" answers in one of these three categories, depending on the answer. As can be seen, the stronger the parents' attitude toward the use of the HL, the higher the value on the scale.

Self-assessment is coded as follows: "Native-like" - 5; "Advanced" - 4; "Intermediate - 3"; "Low - 2"; "None" - 1 (i.e., the higher the self-assessment, the higher the value on the scale). In addition to the values for each of the skills, I tabulated a cumulative assessment by adding up the values for all 
four skills. Interest in language study I tabulated as follows: "Interested" - 2, "Not interested" -1 . I coded self-assessment and interest in the same manner for all the remaining items.

If parents' attitude was associated with higher self-assessment and/or higher interest in HL learning, one would expect a statistically significant positive correlation between these values.

There is a weak positive correlation between parents' attitude and selfassessment $(\mathrm{r}=0.041, \mathrm{p}=0.614 \mathrm{n}=150)$ and between parent's attitude and interest in HL courses $(\mathrm{r}=0.137, \mathrm{p}=0.094, \mathrm{n}=150)$, but it is not statistically significant.

As for self-assessment, the relation is not statistically significant in any of the four skills: parents' attitude versus listening $(r=0.129, p=0.117$, $\mathrm{n}=150)$, speaking $(\mathrm{r}=0.074, \mathrm{p}=0.370, \mathrm{n}=150)$, or reading $(\mathrm{r}=0.009, \mathrm{p}=0.908$, $\mathrm{n}=150$ ).

The lack of statistically significant correlations between parents' attitudes and self-assessment can be explained by external variables, e.g., the fact that more forceful attitudes on behalf of the parents may create a higher bar for self-assessment (i.e., harsher self-assessment) in some respondents. One would need to correlate assessment data with parents' attitudes to investigate this relation further.

The lack of statistical significance between parents' attitude and interest in HL classes (although a positive correlation exists) may be attributed to a relatively small sample of respondents.

b. Visits to the target countries (item 15) vs. self-assessment (item 23) and interest (item 42)

Visits to target countries are coded as follows: "Once a year" - 4; "3-5 times" - 3; "Once or twice" - 2; and "Haven't been there" - 1. I distributed the "Other" answers in one of these categories depending on the answer. As can be seen, the more frequent the travel, the higher the value on the scale.

In the results, I found a positive statistically significant correlation between more frequent travel and a higher general self-assessment $(\mathrm{r}=0.260, \mathrm{p}=0.001, \mathrm{n}=150)$. More frequent HL travel was also positively correlated with self-assessment in all four skills: listening $(r=0.310, p=0.000$, $\mathrm{n}=150)$, speaking $(\mathrm{r}=0.278, \mathrm{p}=0.001, \mathrm{n}=150)$, reading $(\mathrm{r}=0.214, \mathrm{p}=0.009$, $\mathrm{n}=150)$, and writing $(\mathrm{r}=0.166, \mathrm{p}=0.042, \mathrm{n}=150)$. It is particularly worth mentioning that more frequent travel is, as one would expect, more strongly correlated with listening and speaking skills than with reading and writing. This result is very important in incorporating study abroad into heritage language education. As results suggest, it is necessary to place a stronger emphasis on reading and writing skills during the time a student stays abroad.

The results show no statistically significant correlation between more frequent travel and a higher interest in heritage language courses $(r=0.095$, 
$\mathrm{p}=0.246, \mathrm{n}=150$ ). Here again, some respondents may believe that visits to the region suffice and that no courses are needed.

c. Visits to heritage venues (item 41 ) vs. self-assessment (item 23) and interest (item 42)

I coded visits to the heritage venues as follows: "Several times a week" 5; "Once a month" - 4; "Several times a year" - 3; "Once a year" - 2; and "Never" - 1. I distributed the "Other" answers in one of these categories, depending on the answer. As can be seen, the more frequent the visits, the higher the value on the scale.

There is a statistically significant correlation between the visits to heritage venues and a higher general self-assessment $(\mathrm{r}=0.252, \mathrm{p}=0.002$, $\mathrm{n}=150)$ and each of the four skills: listening $(\mathrm{r}=0.205, \mathrm{p}=0.012, \mathrm{n}=150)$, speaking $(\mathrm{r}=0.224, \mathrm{p}=0.006, \mathrm{n}=150)$, reading $(\mathrm{r}=0.230, \mathrm{p}=0.005, \mathrm{n}=150)$, and writing $(r=0.248, p=0.002, n=150)$. Similarly to $H L$ travel, these visits do not influence the interest in HL classes ( $r=-0.103, p=0.211, n=150)$.

d. HL materials (item 28) vs. self-assessment (item 23) and interest

(item 42)

My coding is the following: one point was assigned for any kind of HL materials a respondent had, and a sum of all points was tabulated for each respondent. Overall, the more materials respondents noted, the higher value on the scale the respondent received.

There are moderate to weak statistically significant correlations between more heritage language materials and a higher general selfassessment $(\mathrm{r}=0.263, \mathrm{p}=0.001, \mathrm{n}=150)$. The same holds true for the four skills: listening $(\mathrm{r}=0.273, \mathrm{p}=0.001, \mathrm{n}=150)$, speaking $(\mathrm{r}=0.230, \mathrm{p}=0.005$, $\mathrm{n}=150)$, reading $(\mathrm{r}=0.252, \mathrm{p}=0.002, \mathrm{n}=150)$, and writing $(\mathrm{r}=0.207, \mathrm{p}=0.011$, $\mathrm{n}=150$ ). No statistically significant relation exists between more HL materials and higher interest in HL courses ( $\mathrm{r}=0.069, \mathrm{p}=0.404, \mathrm{n}=150)$.

e. Early exposure (item 38) vs. self-assessment (item 23) and interest (item 42)

I coded early exposure as follows: if in any of the two first developmental periods (0-5 years and 6-12 years) HL was dominant, two points were assigned; one point was assigned for a combination of HL and English; and 0 points for English. I added then the values for these two periods for each respondent.

Strong positive statistically significant correlations between early exposure and higher self-assessment in general $(\mathrm{r}=0.619, \mathrm{p}=0.000, \mathrm{n}=153)$ and in all four skills were noted: listening $(\mathrm{r}=0.482, \mathrm{p}=0.000, \mathrm{n}=150)$, speaking ( $r=0.499, \mathrm{p}=0.000, \mathrm{n}=150)$, reading $(\mathrm{r}=0.463, \mathrm{p}=0.000, \mathrm{n}=150)$, and writing $(\mathrm{r}=0.494, \mathrm{p}=0.000, \mathrm{n}=150)$. There is no significant correlation between early exposure and interest in HL classes $(r=-0.045, p=0.582$, $\mathrm{n}=151$ ). 
f. Home language (item 17) vs. self-assessment (item 23) and interest (item 42)

With respect to coding, I assigned two points for the dominance of HL at home, one point for a mix of HL and English, and 0 points for the dominance of English.

As in the previous category, there are strong statistically significant correlations between home language use and self-assessment in general $(\mathrm{r}=0.422, \mathrm{p}=0.000, \mathrm{n}=149)$ and in all four skills: listening $(\mathrm{r}=0.408, \mathrm{p}=0.00$, $\mathrm{n}=149)$, speaking $(\mathrm{r}=0.456, \mathrm{p}=0.000, \mathrm{n}=149)$, reading $(\mathrm{r}=0.364, \mathrm{p}=0.000$, $\mathrm{n}=149)$, and writing $(\mathrm{r}=0.317, \mathrm{p}=0.000, \mathrm{n}=149)$. One should note in particular that the correlations are stronger in the listening/speaking area, which is expected given the nature of conversation at home. There is no statistically significant correlation between home language and interest in HL classes $(r=-0.094, p=0.254, n=149)$.

g. Language preference (item 48) vs. self-assessment (item 23) and interest (item 42)

In my coding, zero points were assigned if English is preferred language, one point if a mix of the two languages, and two points if HL is preferred.

Language preference for HL over English is correlated with a higher selfassessment in general $(\mathrm{r}=0.386, \mathrm{p}=0.000, \mathrm{n}=150)$ and the four skills: listening $(\mathrm{r}=0.237, \mathrm{p}=0.000, \mathrm{n}=150)$, speaking $(\mathrm{r}=0.324, \mathrm{p}=0.000, \mathrm{n}=150)$, reading $(r=0.428, p=0.000, n=150)$, and writing $(r=0.378, p=0.000, n=150)$. It is particularly interesting that the correlations are stronger in the reading/writing area. Concurrently, there is a weak, statistically significant negative correlation with the interest for classes $(r=-0.169, p=0.000$, $\mathrm{n}=150$ ). Both findings can be explained by the fact that those who prefer HL to English feel secure in all language areas and do not see the need to improve.

Items $\mathrm{d}, \mathrm{e}, \mathrm{f}$, and g clearly show that the role of the parents stands as important. Parents, without overtly expressing interest in HL maintenance, provide their children with materials, enable early exposure to HL, and shape their children's attitudes towards HL, which overall contribute to children's higher self-assessment.

h. Self-assessment (item 23) vs. interest (item 42)

The last investigated relation is between self-assessment and interest in classes. I coded both values as in all previous items.

It is interesting to note that a statistically significant negative correlation exists between a higher interest in HL classes and self-assessment in general $(\mathrm{r}=-0.347, \mathrm{p}=0.000, \mathrm{n}=150)$ and all four skills: listening $(\mathrm{r}=-0.201, \mathrm{p}=0.014$, $\mathrm{n}=150)$, speaking $(\mathrm{r}=-0.296, \mathrm{p}=0.000, \mathrm{n}=150)$, reading $(\mathrm{r}=-0.296, \mathrm{p}=0.000$, $\mathrm{n}=150)$, and writing $(\mathrm{r}=-0.343, \mathrm{p}=0.000, \mathrm{n}=150)$. In particular, those who self-assess high in the reading and writing areas tend to exhibit a lower interest in classes. 
All findings listed in sections 5.1 and 5.2 were taken into consideration in the design of the syllabus, discussed next. I return to selected findings in section 7, using them as the basis for recommendations.

\section{SYLLABUS}

\subsection{DESIGN}

I base the design of the syllabus on results from the fieldwork and interview data analysis, as well as the results obtained from the survey data. The clear preference of students for online courses was the basis of the decision to offer the course in an online format, but with ample interaction with the instructor. ${ }^{9}$ Similarly, varied preferences as to the ethnic variant were addressed by enabling the students to choose the materials either from one or several ethnic variants of BCS. Furthermore, general preference of the sample for improvement of vocabulary range and grammatical accuracy was incorporated into the syllabus. This was accomplished through reading and presentation tasks, reflection on the feedback from the instructor, selected grammatical topics, and other relevant activities.

I designed the course with an eye toward eventual attainment of ILR 3 proficiency by the students. Therefore, both the readings and the presentation topics were designed for this level of language proficiency. Students selected for this course were initially at a strong ILR 2+ level in speaking ("strong advanced high" according to the NCSSFL-ACTFL scale), which was confirmed in a Simulated Oral Proficiency Interview [SOPI]. ${ }^{10}$

\subsection{TESTING}

In the fall semester of the academic year 2011-12, I offered the newly developed model as an alternative for heritage courses in two Arizona State University classes, BCS 311 and BCS 495, in order to test the newly created syllabus. Appendix A provides the designed syllabus and Appendix B illustrates the presentation topics used in the experimental course.

The original two classes are traditionally well-populated with heritage speakers. At the time of the experiment, 11 students in total were enrolled

9 Please note that the discussed design does not preclude relatively simple modifications of the online format into a summer course taught in person, by replacing recorded presentations with in-class projects, independent reading sessions with in-class reading sessions, and other relevant activities.

10 Please note that the instructor is an ACTFL-certified tester. 
in the two classes, eight of whom may be classified as heritage speakers. I presented students with a choice of completing the course using the existing syllabus or selecting the new experimental syllabus. At the beginning of the semester, I sent an explanatory note to students about the new syllabus, encouraging them to consider the new format. Three students selected the new syllabus. In answering the inquiry as to why the remaining five heritage speakers did not, all of them cited "difficult grammar." This is the first valuable finding from the testing of the new format. Even though, as the survey clearly shows, the prospective students seek to improve their grammatical accuracy, the overly technical manner of presentation (as was the case with the materials disseminated via the Blackboard course management system) scared off most of the students who consulted the new syllabus. The lesson learned is that in any format of the course, online or inclass, presentation of the grammatical content, even at this level, needs to be "sugar-coated."

At the beginning and at the end of the course, I administered a simulated Oral Proficiency Interview ${ }^{11}$ with the three students that chose the new syllabus. One participant was already at ILR 3 and remained in that range following course completion. The two other students ranked at ILR $2+$ at both pre-test and post-test stages. Worth noting is that after completing the course based on the new syllabus, there were tangible and substantial improvements in some areas. Most specifically, students improved their ability to support their opinions and speak hypothetically. While there was some progress in grammatical accuracy for the two learners, the cohesiveness of discourse and vocabulary breadth were definitely not at ILR 3. This assessment was based on both the differences in the two SOPIs and various forms of formative assessment that were incorporated into the class throughout the semester (student's class presentations, projects, quizzes, etc.).

While the discussed sample is rather limited and only speaking was tested, the impression still remains that the time at one's disposal during one university semester (or a summer course) is simply insufficient to cross from ILR 2 or 2+ proficiency level to ILR 3 level in BCS, which is a Defense Language Institute difficulty category level 3 language (difficulty level 2 in the new Foreign Service Institute nomenclature). The problem is additionally exacerbated by the fact that all students under the analysis functioned in an English-speaking environment during the course (living outside their parents' home).

11 Instead of OPI, the terminology would rather be SOPI, as the author and interviewer is ACTFL-certified OPI tester for Polish and English, but not BCS. 
Therefore, the second important lesson from this testing is the need for a longer period of time and for a type of immersion, ideally in the target country.

\section{CONCLUSIONS AND RECOMMENDATIONS}

The conclusions and recommendations stemming from this research fall into the following two broad categories:

a. Factors influencing language maintenance in the community, i.e., securing ideal prospective students for heritage language courses.

b. Parameters of the course design, which ideally lead toward full working proficiency in the heritage language.

In considering the factors influencing language maintenance, as the data clearly show, early family exposure, travel to HL countries, visits to HL venues, and the presence of HL materials contribute to a higher selfassessment in language proficiency. While definitive answers can only be obtained by correlating test results with the aforementioned factors (which would require larger-scale research), even the present limited evidence points to the need to strengthen and facilitate HL activities. I envisage a range of programs, from organizing an exchange of materials with the target countries (exchanging English for HL materials, through their diplomatic posts or with relevant institutions, to be disseminated in the HL communities) to outreach in the HL communities by matching funds for HL venues, scholarships to travel to the HL countries, information sessions about the importance of early exposure to the HL, and the like.

One important finding is that a higher self-assessment leads to a less prominent desire to take heritage classes. Both qualitative analysis of the face-to-face interviews and quantitative study of the survey data confirm this. The problem with this attitude toward taking HL classes is that most heritage speakers are not at the ILR 3 proficiency level. In fact, they need heritage language education to attain this level of language proficiency in order to function professionally in BCS. I suggest two strategies that can be adopted in this regard. First, university centres that offer BCS classes, and in particular those which have HL classes, should be strengthened to avert the aforementioned trend at places where BCS programs are being extinguished (some of which are mentioned above). Strengthening such centres, with strong ties to and engagement with heritage communities (outreach, guest lectures, and similar activities), would go a long way toward making the communities realize that classes are indeed necessary, even if speakers sound fluent or perceive themselves to be fluent. Second, information sessions in communities where such university centres do not exist, and thus cannot emphasize the need to formally study one's HL, would additionally 
contribute to changing the often erroneous impression that "fluent" heritage speakers do not need classes.

Creating a national centre for BCS HL maintenance and learning, which could be affiliated with a prominent university department offering BCS for heritage speakers, would be an optimal solution to coordinate all the aforementioned activities. This centre could be used as a case study for other similar languages. While more populous strategic languages (MSA, Mandarin, Russian, and others) have their HL population covered under the Flagship program (http://www.thelanguageflagship.org), equally strategically important HLs like BCS remain bereft of such organized institutional support. To bridge the clear gap, smaller-scale centres can be constructed and organized to facilitate exchange of the materials, coordinate outreach activities, promote the courses, and carry out various other relevant activities.

With respect to the design of the new course, a modular hybrid course delivered online during one semester (during the regular academic year or over the summer), followed by a three-month supervised study abroad, would be optimal. The course should be offered for BCS as a whole, but students should be given a choice to complete all activities with their ethnic variant alone, if they so desire. The reasons for such recommendations are as follows:

First, an additional immersion period seems to give a realistic prospect of crossing from ILR 2+ to ILR 3, specifically because the vocabulary range, discourse complexity, and cultural competence require more time and immersion. Second, there are numerous reasons why online delivery of the first module of the course is preferred: (a) most respondents prefer such delivery, and even those who prefer in-class delivery cannot travel somewhere else; (b) online delivery is available to those who live outside the areas with university centres; and (c) such a format offers more flexibility in terms of the ethnic variants (and some portion of the prospective student population is focused on only one ethnic variant). Third, supervised immersion abroad would enable the envisaged stay abroad to be much more productive, in particular because the students would be asked to engage in more formal activities, such as conducting research about politics, culture, and other subjects, as well as having opportunities to speak with academics, political leaders, and ordinary citizens. The format of the supervised immersion should be kept open and flexible to accommodate students' professional interests (for example, an economics major would have different activities from an art history major), but in each instance they would include formal oral communication, reading and summarizing daily news, writing formal reports, and other activities. Fourth, a common BCS course is preferred over separate ethnic courses for strictly practical reasons. It is difficult to recruit enough people for a common course, and 
recruiting for separate ethnic courses would be close to impossible. One should note, however, that the course should offer full flexibility in enabling students to work with their ethnic variant alone or with several of the variants (given that preferences were rather dispersed on this score). Moreover, the immersion part would be performed in a region of the former Yugoslavia dominated by one ethnic group (as ethnically-mixed areas are extremely rare), which would be another accommodation for those who seek to work with their ethnic variant without any interference from other ethnic variants (i.e., they would typically function within a monoethnic environment).

The aforementioned BCS HL centre would be most useful in coordinating the proposed new course, offering the online component, preparing and sending students abroad, and coordinating target-country immersion programs.

\section{Works Cited}

NCSSFL-ACTFL. "Can-Do Statements: Progress Indicators for Language Learners." ACTFL, 2012, www.actfl.org/sites/default/files/pdfs/Can-Do_Statements.pdf. Accessed 3 Dec. 2016.

"Annual Census of College Enrolment." American University, http://www1.american.edu/research/CCPCR/COLLEGEENROLL.htm. Accessed Oct. 2011.

Brinton, Donna, et al. Heritage Language Education: A New Field Emerging. Routledge, 2008.

“Canadian Language Benchmarks." Citizenship and Immigration Canada, 2012, www.cic.gc.ca/english/pdf/pub/language-benchmarks.pdf. Accessed 23 Sept. 2015.

Carreira, Maria, and Olga Kagan. "The Results of the National Heritage Language Survey: Implications for Teaching, Curriculum Design, and Professional Development." Foreign Language Annals, vol. 44, no. 1, 2011, pp. 40-64.

Chhuon, Vichet. "Adolescent Heritage Speakers of Less Commonly Taught Languages in the United States." Language and Linguistics Compass, vol. 5, no. 9, Sep 2011, pp. 666-76.

"Common European Framework of Reference for Languages: Learning, Teaching Assessment." Council of Europe, Policy Planning Unit, 2001, www.coe.int/t/dg4/linguistic/source/framework en.pdf. Accessed 26 Sept. 2015.

Creswell, John W. Research Design: Qualitative, Quantitative, and Mixed Method Approaches. Sage Publications, 2003.

Cummins, Jim. "A Proposal for Action: Strategies for Recognizing Heritage Language Competence As a Learning Resource Within the Mainstream Classroom." The Modern Language Journal, vol. 80, no. 4, 2005, pp. 585-92. 
"Detailed List of Languages Spoken at Home for the Population 5 Years and Over by State: 2000." U.S. Census Bureau, 2009. www2.census.gov/programssurveys/decennial/2000/phc/phc-t-20/tab05.pdf. Accessed 20 Sept. 2016.

Greenberg, Robert. Language and Identity in the Balkans: Serbo-Croatian and Its Disintegration. Oxford University Press, 2004.

Heritage Languages in America. Alliance for the Advancement of Heritage Languages, http://www.cal.org/heritage/index.html. Accessed 1 Sept. 2011.

Heritage Language Journal, http://www.heritagelanguages.org. Accessed 26 Sept. 2015.

Herzog, Martha. "An Overview of the History of the ILR Language Proficiency Skill Level Description and Scale." Interagency Language Roundtable. http://www.govtilr.org/Skills/index.htm. Accessed 9 Sept. 2015.

Kagan, Olga. "In Support of a Proficiency-Based Definition of Heritage Language: The Case of Russian." International Journal of Bilingual Education \& Bilingualism, vol. 8, no. 2-3, 2005, pp. 213-21.

Kagan, Olga, et al. Russian for Russians: Textbook for Heritage Speakers. Slavica, 2003. Kondo-Brown, Kimi. "Bilingual Heritage Students' Language Contact and Motivation." Motivation and Second Language Acquisition, edited by Dörnyei Zoltan and Schmidt Richard, Second Language Teaching \& Curriculum Center, 2001, pp. 43359.

Kordić, Snježana. “Le Serbo-Croate Aujourd'hui: Entre Aspirations Politiques et Faits Linguistiques." Revue des Etudes Slaves, vol. LXXV, no. 1, 2004, pp. 31-43.

Lee, Jin Sook. “Through the Learners' Eyes: Reconceptualizing the Heritage and NonHeritage Learner of the Less Commonly Taught Languages." Foreign Language Annals, vol. 38, no. 4, 2005, pp. 554-67.

Lussier, Hubert. "Proposal for a Common Framework of Reference for Languages for Canada." European Language Portfolio, 2011, http://elpimplementation.ecml.at/IMPEL/Documents/Canada/ProposalofaCFRforCanada /tabid/122/language/fr-FR/language/en-GB/Default.aspx. Accessed 23 Sept. 2015.

Moreira Flores, Christina Maria. "Understanding Heritage Language Acquisition. Some Contributions from the Research on Heritage Speakers of European Portuguese." Lingua, vol. 164, pt. B, 2015, pp. 251-65.

National Heritage Language Center. http://www.nhlrc.ucla.edu/nhlrc.

Peyton, Joy Kreeft, et al. Heritage Languages in America: Preserving a National Resource. Center for Applied Linguistics, 2001.

Polinsky, Maria, and Olga Kagan. "Heritage Languages: In the 'Wild' and in the Classroom." Language and Linguistics Compass, vol. 1, no. 5, 2007, pp. 368-95.

Rothman, Jason. "Heritage Speaker Competence Differences, Language Change, and Input Type: Inflected Infinitives in Heritage Brazilian Portuguese." International Journal of Bilingualism, vol. 11, no. 4, 2007, pp. 359-89.

Ryan, Camille. "Language Use in the United States: 2011." US Census Bureau, 2013, www.census.gov/prod/2013pubs/acs-22.pdf. Accessed 23 Sept. 2015.

Šipka, Danko, and Rasio Dunatov. "Serbokroatistika u SAD." Odjek, vol. XLI, no. 12, 1988, p. 21. 
Šipka, Danko. "Re: Serbo-Croatian (BCMS) Programs.” The Linguist List, 13 Mar. 2008, SEELANGS, http://listserv.linguistlist.org/pipermail/seelang/2008-March.txt. Accessed 3 Dec. 2016.

Tatar, Ruba. Parent's Role in Their Children's Development and Maintenance of the Heritage Language. Indiana University of Pennsylvania, 2015. 


\section{APPENDIX A}

THE SYLLABUS

\section{BCS for Heritage Speakers}

Heritage speaker alternative to BCS 311, BCS 312, and BCS 495

Contact with the instructor: Per e-mail (Danko.Sipka@asu.edu) at any time. Per telephone 4806378427 T 6:00-9:00 PM. In the office LL 419B T, TH 10:30 am - 12:00 pm (e-mail me on the previous day to let me know when to expect you)

\section{COURSE DESCRIPTION}

This course builds upon the student's advanced proficiency and builds reading and listening skills to the level where the student is able to read within a normal range of speed and with almost complete comprehension a variety of authentic prose material on unfamiliar subjects and to understand the essentials of all speech in a standard dialect including technical discussions within a special field. Students should furthermore be able to write with some precision and in some detail about most common topics and show considerable ability to communicate effectively on topics relating to particular interests and special fields of competence.

\section{Student LeARning OUTCOMES}

The attainment of ILR 3 skills in reading and listening and ILR 2+ skills in speaking and writing (see http://www.govtilr.org/Skills/ILRscale1.htm for the description of the levels).

\section{LiSTING OF ASSIGNMENTS (SEE 5. BELOW FOR MATERIALS)}

You are expected to move along the schedule described in point six of this document. During each of the first seven two-week periods you are requested to submit the following:

1. Read one short story of your choice (see section 5 ) and submit a onepage critical evaluation of that reading in BCS

2. Read one newspaper article from the subject-matter area indicated in 6. Submit its half-page summary BCS and a list of relevant grammatical structures in the entire issue of that newspaper

3. Listen to one radio or television news program, submit its half-page summary in BCS and a list of relevant grammatical structures

4. Record and submit a presentation on the subject-matter area indicated in 6. 
5. Analyze and offer solutions to the problem areas indicated in the feedback from the instructor

The last two-week period comprises bonus materials.

\section{Grading Policies And Percentages:}

The following scale will be used: 98 and higher $\% A+, 95-98 \% A, 90-94 \%$ A-, 85-89\% B+, 80-84\% B, 75-79\% B-, 70-74\% C+, 65-69\% C, 60-64\% D, 59\% and lower $\mathrm{E}$.

By completing all five assignments listed in the section 3 of this syllabus in each of the seven two-week periods students will earn $13 \%$ toward the grade (a total of $91 \%=7 \times 13$ ). Additional $9 \%$ will be earned in the Oral Proficiency Interview administered in the conversation session of the seventh two-week period.

$10 \%$ bonus points can be earned during the last two-week which makes a total of $110 \%$ possible to be earned during the course.

\section{REQUIRED READINGS}

SS: Short Stories: Enes Durakovic, Antologija bošnjačke pripovjetke XX vijeka, Sarajevo, 1995 (Bosniak); Miroslav Šicel, Antologija hrvatske kratke priče, Disput, Zagreb, 2001 (Croatian), Miroslav Josić-Višnjić, Antologija srpskih pripovedača XIX i XX veka, Beograd, 1999 (Serbian) or any other in agreement with the instructor

G: Grammar: Browne, Wayles and Theresa Alt, A handbook of Bosnian, Croatian, and Serbian, http://www.seelrc.org:8080/grammar/mainframe.jsp?nLanguageID=1

N: Newspapers: http://www.avaz.ba (Bosniak), http://www.jutarnji.hr (Croatian), http://www.politika.rs (Serbian) or any other in agreement with the instructor

TVR: TV and radio: http://www.rtvfbih.ba/loc/ (Bosniak), http://www.hrt.hr (Croatian), http://www.rts.rs (Serbian) or any other in agreement with the instructor

PT: A list of presentation topics (distributed by the instructor via BlackBoard)

L: Lectures about relevant grammatical structures (distributed by the instructor via BlackBoard)

Course itinerary:

The assignments are due at the end of each of the first seven even weeks of the course and they are described in section 3 of this document. 


\section{TABLE 1}

\section{COURSE ITINERARY}

\begin{tabular}{|c|c|c|c|c|}
\hline Week & Structures & $\begin{array}{l}\text { Thematic } \\
\text { area }\end{array}$ & $\begin{array}{l}\text { Forms of } \\
\text { expression }\end{array}$ & $\begin{array}{l}\text { Materials, see } 5 . \\
\text { above for } \\
\text { abbreviations }\end{array}$ \\
\hline $1-2$ & $\begin{array}{l}\text { Less } \\
\text { common } \\
\text { past tense } \\
\text { forms }\end{array}$ & History & $\begin{array}{l}\text { Relating about } \\
\text { past events }\end{array}$ & SS,G,N,TVR,PT,L \\
\hline $3-4$ & $\begin{array}{l}\text { Modal and } \\
\text { phase verbs }\end{array}$ & $\begin{array}{l}\text { Holidays and } \\
\text { traditions }\end{array}$ & Value statements & SS,G,N,TVR,PT,L \\
\hline $5-6$ & $\begin{array}{l}\text { Passive } \\
\text { voice }\end{array}$ & $\begin{array}{l}\text { Literary } \\
\text { traditions }\end{array}$ & $\begin{array}{l}\text { Making } \\
\text { comparisons }\end{array}$ & SS,G,N,TVR,PT,L \\
\hline $7-8$ & $\begin{array}{l}\text { Participles } \\
\text { and gerund }\end{array}$ & $\begin{array}{l}\text { Art, } \\
\text { Architecture, } \\
\text { Music }\end{array}$ & $\begin{array}{l}\text { Hypothetical } \\
\text { statements }\end{array}$ & SS,G,N,TVR,PT,L \\
\hline $9-10$ & $\begin{array}{l}\text { Simple } \\
\text { sentence } \\
\text { syntax }\end{array}$ & Workplace & $\begin{array}{l}\text { Dealing with } \\
\text { complications }\end{array}$ & SS,G,N,TVR,PT,L \\
\hline $11-12$ & Word order & $\begin{array}{l}\text { School } \\
\text { system }\end{array}$ & $\begin{array}{l}\text { Autobiographical } \\
\text { information }\end{array}$ & SS,G,N,TVR,PT,L \\
\hline $13-14$ & $\begin{array}{l}\text { Multi- } \\
\text { clause } \\
\text { sentence } \\
\text { architecture }\end{array}$ & $\begin{array}{l}\text { Healthcare } \\
\text { system }\end{array}$ & $\begin{array}{l}\text { Making } \\
\text { predictions }\end{array}$ & SS,G,N,TVR,PT,L \\
\hline $15-16$ & $\begin{array}{l}\text { Informal } \\
\text { colloquial } \\
\text { language, } \\
\text { allegro } \\
\text { speech }\end{array}$ & Subcultures & Quarrelling & $\begin{array}{l}\text { Bonus materials } \\
\text { to be selected } \\
\text { based on the } \\
\text { student's } \\
\text { interest }\end{array}$ \\
\hline
\end{tabular}

\section{A STATEMENT ON ACADEMiC Dishonesty}

Please consult the following link: http://provost.asu.edu/academicintegrity.

\section{A Disability Policy Statement}

Establishing Eligibility for Disability Accommodations: Students who feel they will need disability accommodations in this class but have not registered with the Disability Resource Center (DRC) should contact DRC immediately. Their office is located on the first floor of the Matthews Center Building. DRC staff can also be reached at: 480-965-1234 (V), 480-965-9000 
(TTY). For additional information, visit: www.asu.edu/studentaffairs/ed/drc. Their hours are 8:00 AM to 5:00 PM, Monday through Friday. 


\section{APPENDIX B}

\section{PRESENTATION TOPICS}

Presentation topics used in the BCS heritage class (based on ACTFL OPI cards).

Please record a 10-minute presentation on the following topic in each of the two-week periods:

Week 1-2: Energy seems to be the major concern for the new millennium. In your opinion, what have been the causes for the depletion of our resources and the impact that the energy crisis may have on the future of the world.

Week 3-4: Reading as a social practice has changed through time. In your opinion, what is the place and the importance of reading in contemporary life.

Week 5-6: There has been much discussion recently about education reform. Some argue that student performance, such as standardized test scores, should be used to evaluate teachers while other believe that given the disparities in our society, this is simply unfair. Could you please compare these two approaches and express your opinions about both of them.

Week 7-8: The problem of child obesity is well documented in the United States. Imagine a hypothetical situation in which you are appointed the Health and Social Services. Please state what would you do to solve this problem and why would you take that particular course of action.

Week 9-10: Imagine that you run an organization of some kind, for example, a student club, which received an annual budget to enable its activities. Imagine further that this year, in light of the current budgetary crisis, you did not get any funds. Please call your funding agency and explain why it is important that you be funded this year despite the crisis.

Week 10-12: Please reflect on you course of education. Please state what, in your opinion, was positive in it, what was negative. Also, if you were in the shoes of your teachers, what would you have done differently and why. 